\title{
Kinetics of joint formation during diffusion induced solid-state bonding of titanium and magnesium alloys
}

\author{
Kavian O. Cooke PhD \\ Faculty of Engineering and Informatics, University of Bradford, Richmond Road BD7 1DP, West \\ Yorkshire, United Kingdom k.cooke1@ bradford.ac.uk
}

\begin{abstract}
This study explores the diffusion bonding of titanium to magnesium. The microstructural evolution and intermetallic compounds formed within the bond region are studied. The microstructure and composition of the bonds were characterized using a Scanning Electron Microscope (SEM) equipped with Energy Dispersive Spectroscopy (EDS). The mechanical properties of the bonds were evaluated using a micro-hardness test to determine the hardness variation across the joint region, while shear strength measurements were used to assess the joint strength. The results indicated that solid-state diffusion bonding of Ti6Al-4V and $\mathrm{Mg}(\mathrm{Az31})$ lead to the formation of $\mathrm{Ti}_{3} \mathrm{Al}$ and $\mathrm{Ti}_{2} \mathrm{Mg}_{3} \mathrm{Al}_{18}$ reaction layers within the joint region. Evaluation of the mechanical properties of the bonds revealed that the bond strength increased with increase bonding time to $116 \mathrm{MPa}$ at a bond time of $1 \mathrm{hr}$. The joint formation and strength were attributed to dispersion strengthening due to the nucleation of dispersed intermetallic compounds at the joint interface.
\end{abstract}

Keywords; Diffusion Bonding, Titanium, Magnesium, Intermetallic, Solid-State

\section{INTRODUCTION}

The growing concerns regarding fuel consumption within the aerospace and transportation industries make the development of fuel-efficient systems a significant engineering challenge [1]. Currently, materials are selected because of their abilities to satisfy engineering demands for good thermal conductivity, strength to weight ratio, tensile strength, and corrosion resistance. Titanium is attractive for use in aerospace and transportation because, in addition to satisfying the mechanical and thermal requirements, its passivation behaviour allows for its application in industries requiring excellent corrosion resistance [2]. At room temperature titanium has a hexagonal close-packed (hcp) crystal structure which is referred to as the alpha phase, however, at temperatures above $883{ }^{\circ} \mathrm{C} \mathrm{Ti}$ undergoes a polymorphic transformation which changes the alpha phase to a beta phase having a body-centred cubic (bcc) structure. Magnesium, on the other hand, maintains its hcp crystal structure throughout

Digital Object Identifier (DOI):

http://dx.doi.org/10.18687/LACCEI2020.1.1.287

ISBN: 978-958-52071-4-1 ISSN: 2414-6390 temperature fluctuations. Additionally, $\mathrm{Mg}$ is the lightest structural metal available and like $\mathrm{Ti}$ has excellent thermal conductivity and strength-to-weight ratio. However, there are several limitations to using magnesium, for example, the chemical reactivity of the material. Additionally, chemical reactions between $\mathrm{Mg}$ and other elements can lead to the formation of intermetallic compounds, such as $\mathrm{Mg}_{17} \mathrm{Al}_{12}$ which forms from a eutectic reaction between $\mathrm{Mg}-\mathrm{Al}$ alloys or $\mathrm{Ti}_{2} \mathrm{Mg}_{3} \mathrm{Al}_{18}$ which forms in ternary systems of $\mathrm{Ti}, \mathrm{Mg}$ and Al [3][4]. The application of the Hume-Rothery rules to these two alloys shows that while both $\mathrm{Mg}$ and $\mathrm{Ti}$ have hcp crystal structure at room temperature the differences in the atomic radii, electronegativity and the number of valence electrons significantly limits the solubility of $\mathrm{Mg}$ in $\mathrm{Ti}$ and restricts the types of compounds that can form at the interface [5].

Multi-material structures provides the most efficient design solution to lightweigthing engineering challenges. The utilization of several metals in the construction of hybrid (multi-material) structures are constrained by the ability of the available welding/joining technologies to join dissimilar materials together, even within a single class of material (e.g. metals) [6][7][8]. Fusion welding process is the method used for joining similar metals. However, the application of any fusion welding technique to join dissimilar metals presents additional difficulties, the first one being; the reaction of the two metals at the joint interface can create compounds that may have unfavourable properties [9][10]. Another limitation to the use of these alloys includes galvanic corrosion due to differences in electrode potential values between the materials. Because of these challenges, dissimilar welding of advance alloys such as titanium and magnesium is limited, even though these materials hold significant potential for product development.

Dissimilar joining of titanium and magnesium has been previously attempted using transient liquid diffusion bonding as a way of limiting intermetallic formation at the bond interface [11]. The process utilizes an interlayer which forms a liquid either by direct melting due to heating beyond the melting point of the interlayer or the formation of a eutectic reaction between the interlayer and the base metal [12]. The method has been shown to promote joining by removing surface oxide and ensuring metal-to-metal contact. Sheng et al. [9] created a $\mathrm{Ti} / \mathrm{Mg}$ lap joint using tungsten inert gas 
welding [13][14]. Joint formation and the strength developed in diffusion bonds have been shown to relate to the width of the reaction layer formed at the interface during joining. The thickness of the reaction layer formed during diffusion bonding can be estimated by the parabolic power law shown in Equation 1

$d=k t^{n}$

Where $d$ is the width of the reaction layer, $k$ is the reaction rate factor, $t$ the diffusion time, and $n$ the time exponent. The use of the parabolic law suggests that the growth kinetics of the intermetallic layer is controlled by inter-diffusion (volume diffusion); therefore, diffusion time is estimated to be $t^{1 / 2}$ where $n=0.5$. Alternatively, if the growth kinetics were controlled by interfacial diffusion, the time exponent would be $n=1$ [15]. If grain growth takes place in the reaction layer, then $n$ becomes smaller than 0.5 for a boundary diffusion ratecontrolling process. If $\mathrm{n}$ becomes equivalent to 0.25 , the grain growth obeys the power law which means that the mean grain size of the intermetallic layer increases in proportion to the square root of the bonding time [16].

This study investigates the dissimilar solid-state joining of titanium to magnesium and studies the microstructural evolution and intermetallic compounds formed within the bond region that promotes a metallurgical bonding between $\mathrm{Ti}$ and $\mathrm{Mg}$. The nature of the layers formed at the interface was also discussed in terms of the thermodynamic and kinetic factors influencing the reaction layer formation and the impact on the bond strength.

\section{MATERIALS AND METHODS}

\section{A. Materials}

In this study, commercially available Titanium (Ti-6Al-4V) and wrought magnesium (AZ31) were used to prepare the Ti-Mg couples by solid-state diffusion bonding. The compositions of the materials studied are listed in Table 1. The properties of $\mathrm{Ti}$ and $\mathrm{Mg}$ are listed in

Table 2 and shows the significant differences between the properties of the two alloys studied.

Table 1: Chemical composition (wt. \%) of the materials used in this study

\begin{tabular}{lllllllll}
\hline & Ti & Si & Mn & Mg & Zn & Ag & V & Al \\
\hline $\begin{array}{l}\text { Ti- } \\
\text { 6Al-4V }\end{array}$ & Bal. & 0.15 & 0.23 & 2.7 & 0 & 0.86 & 4 & 6 \\
\hline $\begin{array}{l}\text { Mg } \\
(\text { AZ31) }\end{array}$ & & 0.03 & 0.37 & Bal. & 1.04 & 0 & 0 & 2.66 \\
\hline
\end{tabular}

Table 2: Properties of the materials used in this study [12].

\begin{tabular}{|l|l|l|}
\hline Properties & Ti & Mg \\
\hline Crystal Structure & $\begin{array}{l}\text { HCP to } 885^{\circ} \mathrm{C} \\
\text { BCC above the } \\
\text { beta transus }\end{array}$ & HCP \\
\hline $\begin{array}{l}\text { Thermal Conductivity } \\
\mathrm{W} / \mathrm{m}-\mathrm{K}\end{array}$ & 22 & 160 \\
\hline $\begin{array}{l}\text { Thermal Expansion } \\
\text { Coefficient } \mathrm{K}^{-1}\end{array}$ & $8.6 \times 10^{-6}$ & $2.48 \times 10^{-5}$ \\
\hline Melting Point ${ }^{\circ} \mathrm{C}$ & 1670 & 650 \\
\hline $\begin{array}{l}\text { Specific Heat Capacity } \\
\mathrm{J} / \mathrm{g}-{ }^{\circ} \mathrm{C}\end{array}$ & 0.5263 & 0.1080 \\
\hline
\end{tabular}

\section{B. Sample preparation and bonding process}

The samples were prepared for bonding by cutting the Ti and $\mathrm{Mg}$ alloys to a dimension of $10 \times 10 \times 5 \mathrm{~mm}$. A hole was drilled in the Ti sample to a depth of $3 \mathrm{~mm}$ at $1 \mathrm{~mm}$ from the bonding interface. The bonding surfaces were prepared to 2500 grit $\mathrm{SiC}$ finish and subsequently polished to $1 \mu \mathrm{m}$ using a particle impregnated carrier paste and then cleaned in an acetone bath. To study the effect of interlayer composition, the titanium samples were electrodeposited with $\mathrm{Ni} / \mathrm{Al}_{2} \mathrm{O}_{3}$ coating. The deposition process was described in an earlier study [17],[18].

The specimens were assembled at room temperature and placed on the lower platen within the induction coil and an ungrounded k-type thermocouple inserted into the hole located approximately $1 \mathrm{~mm}$ from the joint interface. When $2 \times 10^{-3}$ Torr vacuum was achieved, the assembly was heated to the bonding temperature $\left(500{ }^{\circ} \mathrm{C}\right)$.

The specimens were brought to the joining temperature at a heating rate of $65^{\circ} \mathrm{C} / \mathrm{min}$ and then held at that temperature for bonding times ranging from 10-60 minutes. At the end of the bonding process, the power was switched off, and the specimens were cooled to room temperature in vacuum. The bonded samples were sectioned transversely to the bond-line by an abrasive saw and mounted in Bakelite. The mounted specimens were prepared according to ASTM standard B253. Each sample was ground progressively on silicon carbide papers from $240-800$ grit, followed by a final polish to $1 \mu \mathrm{m}$ finish. Kroll's reagent was used as the etchant to reveal the grain structure.

\section{Mechanical testing}

The shear strength of the Ti/Mg bonds was determined using a single lap-joint which was loaded into a shear test fixture and pulled in tension by a GUNT (WP 300 Universal materials tester, Germany) tensile testing machine. The samples were loaded to ensure that each specimen experienced pure shear stress across the bond interface. The bond strength was calculated by dividing the maximum load by the bond area. For each bonding condition, three specimens 
were tested, and the average value used to determine the shear strength (bond strength). Micro-hardness testing was performed on the cross-section of the joints using a Leitz micro-hardness tester. Indentations were made at $100 \mu \mathrm{m}$ spacing using a diamond tip indenter loaded with $0.1 \mathrm{~kg}$ and applied for $30 \mathrm{~s}$, after which the length of the diagonals was measured, and the hardness number calculated using Equation 1.

\section{Microstructural evaluation}

Microscopic examination of the bonded joints was performed using a Leitz optical microscope and an Oxford (FEI Quanta 400 Oxfordshire U.K.) scanning electron microscopy (SEM) equipped with INCA $\mathrm{x}$-sight $\mathrm{x}$-ray. Quantitative compositional analyses were carried out using energy dispersive spectroscopy (EDS). X-ray diffractometry (XRD) measurements were done using a Bruker XRD machine adjusted to the following settings: $40 \mathrm{kV}, 40 \mathrm{~mA}$, step-size $0.05^{\circ}$ for 2-Theta ranging from $10^{\circ}$ to $100^{\circ}$ and measuring 1 second per step.

\section{RESULTS AND DISCUSSION}

\section{E. Microstructural characterization}

Fig. 1 (A) shows the SEM micrograph of the sample bonded for 10 minutes. The joint appears to present good bonding between the Ti and $\mathrm{Mg}$ sample due to the absence of void, cracks or porosities. When the bonding time was increased to 30 minutes, it was observed that a reaction layer formed on the $\mathrm{Mg}$-side of the joint interface, as shown in Fig. 1

Further increase of the bonding time to 60 minutes resulted in an increase of the width of the reaction layer, as shown in Fig. 2(B). Magnified sections of the joint interface for the sample bonded for 60 minutes is presented in Fig. 2(C) and (D). The compounds formed at the interface appears to be in the form of dispersed particles approximately $20 \mu \mathrm{m}$ in length.

EDS analysis of joint region as a function of bonding time using compositional maps confirmed the inter-diffusion of $\mathrm{Ti}$, $\mathrm{Mg}$ and $\mathrm{Al}$ during the bonding process. The maps show that as the bonding time increase the depth to which $\mathrm{Mg}$ diffused into the Ti-side increased (see Fig. 3). However, given the differences in the diffusion coefficient of $\mathrm{Ti}$ and $\mathrm{Mg}$ as presented in Table 2, it appears that rate of diffusion of Ti into $\mathrm{Mg}$ is prolonged due to the difference in the interdiffusion depth of $\mathrm{Mg}$ and $\mathrm{Ti}$ as indicated in the elemental maps. Additionally, the results also showed that $\mathrm{Al}$ diffuses from both the $\mathrm{Mg}$ and the Ti alloy to the interface.
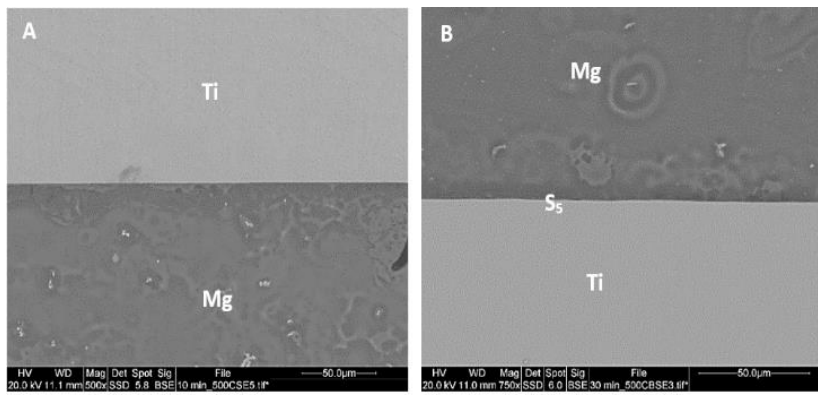

Fig. 1: Solid-state diffusion bonding of $\mathrm{Ti}$ and $\mathrm{Mg}$ for; (A) 10 minutes and (B) 30 minutes.
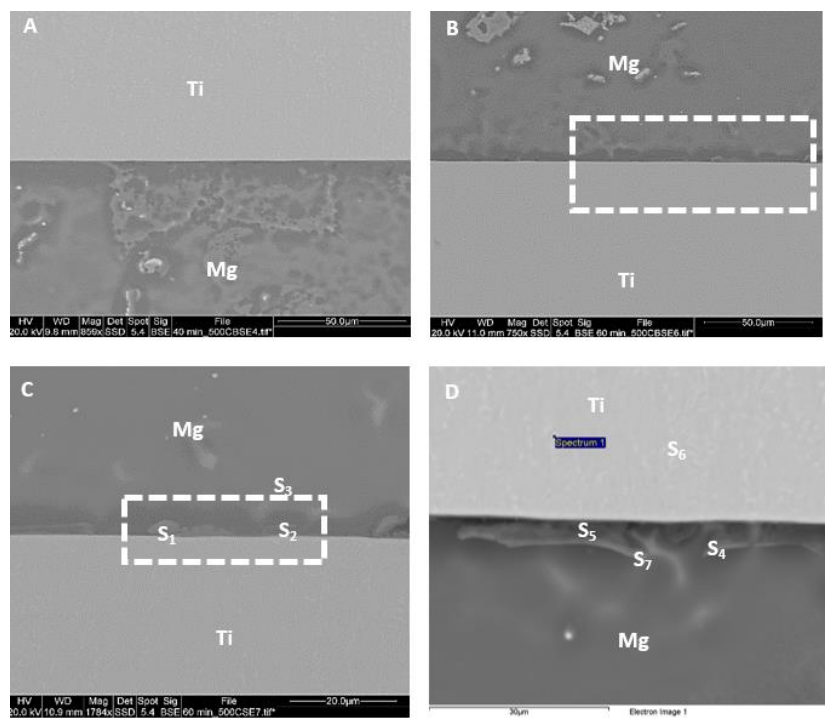

Fig. 2: Solid-state diffusion bonding of Ti and Mg for: (A) 40 minutes; (B) 60 minutes; (C) Detailed view of the reaction layer at the bond interface; (D) imperfection at the bond interface showing compositional variation.

Further EDS point analysis of the samples bonded for 30-60 minutes, revealed the formation of several compounds at the bond interface. The composition of each compound identified and the likely molecular formula is shown in Table 3. The results show that when the sample is held at the bonding temperature; $\mathrm{Al}$ reacts with $\mathrm{Ti}$ and $\mathrm{Mg}$ to form $\mathrm{TiAl}_{3}$ and $\mathrm{Ti}_{2} \mathrm{Mg}_{3} \mathrm{Al}_{18}$ intermetallic compounds at the Ti interface. The $\mathrm{Mg}_{17} \mathrm{Al}_{12}$ intermetallic compounds appear to have formed at the $\mathrm{Mg}$ grain boundaries. The $\mathrm{Mg}_{17} \mathrm{Al}_{12}$ compound is believed to have been produced by a eutectic reaction between $\mathrm{Al}$ and $\mathrm{Mg}$.

The joint formation was attributed to metallurgical bonding driven, leading to the formation of $\mathrm{TiAl}_{3}$ and $\mathrm{Ti}_{2} \mathrm{Mg}_{3} \mathrm{Al}_{18}$. Additionally, the differences in the properties of $\mathrm{Ti}$ and $\mathrm{Mg}$ are believed to contribute to achieving good contact during the bonding process. It is expected that the differences in the melting temperature of the two alloys that at the bonding temperature of $500{ }^{\circ} \mathrm{C}$ the $\mathrm{Mg}$ sample with plastically deform to ensure complete contact with the Ti sample. An analysis of the surface roughness of the polished surfaces of the $\mathrm{Mg}$ and Ti samples bonded revealed Ra values of $41 \mu \mathrm{m}$ and $5.3 \mu \mathrm{m}$ for the $\mathrm{Ti}$ and $\mathrm{Mg}$ samples, respectively. The differences in the surface roughness of the alloys would ensure the as $\mathrm{Mg}$ is deformed at the bonding temperature the Ti asperities would protrude into the surface of the $\mathrm{Mg}$-sample. 


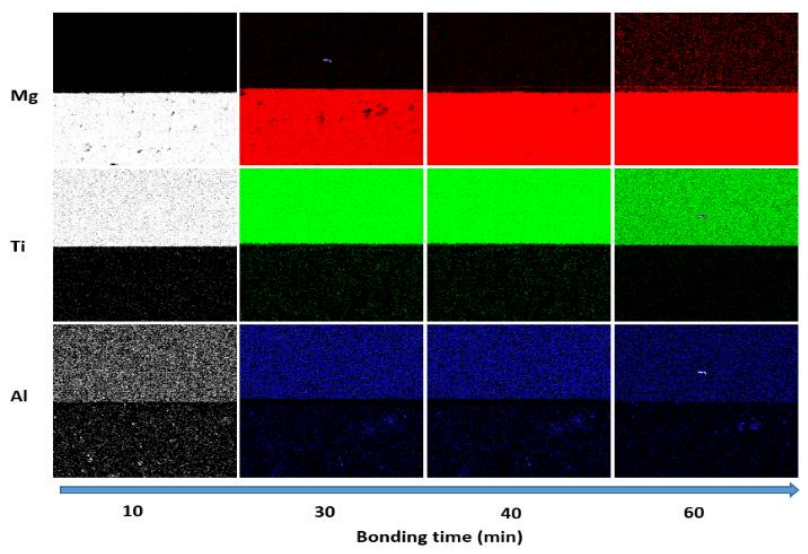

Fig. 3: EDS compositional maps of the diffusion bonds as a function of bonding time.

Table 3: EDS analyses showing the compositional variation across the interface of a sample bonded for 60 minutes

\begin{tabular}{|l|l|l|l|l|l|}
\hline Spectrum & $\mathbf{T i}$ & $\mathbf{M g}$ & $\mathbf{A l}$ & $\mathbf{O}$ & Phase \\
\hline $\mathrm{S}_{1}$ & 9.06 & 46.81 & 3.08 & 31.2 & $\begin{array}{l}\mathrm{Mg}+ \\
\mathrm{Ti}_{2} \mathrm{Mg}_{3} \mathrm{Al}_{18}\end{array}$ \\
\hline $\mathrm{S}_{2}$ & 25.84 & 47.10 & 2.87 & 33.28 & $\begin{array}{l}\mathrm{MgO} \\
\mathrm{Mg}_{17} \mathrm{Al}_{12}\end{array}$ \\
\hline $\mathrm{S}_{3}$ & 0.22 & 89.08 & 1.80 & 4.15 & $\mathrm{Mg}$ \\
\hline $\mathrm{S}_{4}$ & 54.49 & 8.80 & 0.37 & 21.87 & $\mathrm{Ti}+\mathrm{MgO}$ \\
\hline $\mathrm{S}_{5}$ & 89.03 & 1.71 & 5.88 & 0 & $\mathrm{Ti}_{3} \mathrm{Al}$ \\
\hline $\mathrm{S}_{6}$ & 89.97 & 0.55 & 5.83 & 0 & $\mathrm{Ti}_{3} \mathrm{Al}$ \\
\hline $\mathrm{S}_{7}$ & 56.33 & 12.39 & 0.47 & 21.23 & $\mathrm{Ti}+\mathrm{MgO}$ \\
\hline
\end{tabular}

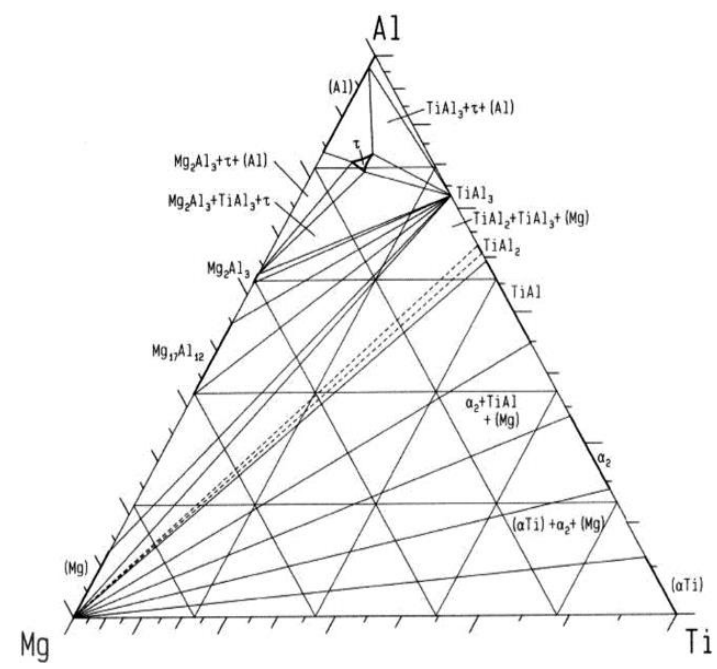

Fig. 4: Ti-Mg-Al ternary phase diagram [19]

\section{F. Kinetics of joint formation}

According to the Ti-Mg-Al ternary phase diagram (see Fig. 4 ), the following phases are likely to form at the bonding temperature and pressure used in this study. These phases include $\mathrm{Mg}_{2} \mathrm{Al}_{3}, \mathrm{Mg}_{17} \mathrm{Al}_{12}, \mathrm{TiAl}_{3}$ and $\mathrm{TiAl}_{2}$ [3]. According to the literature, the Gibbs energy for the formation of $\mathrm{TiAl}_{3}$ is approximately $234 \mathrm{~kJ} / \mathrm{mol}, \mathrm{TiAl}_{2}$ is $237 \mathrm{~kJ} / \mathrm{mol}$ [4]. The diffusion of $\mathrm{Al}$ to the bond interface from Ti-side to the $\mathrm{Mg}$ side led to the formation of a compound having a stoichiometric composition of $\mathrm{Mg}_{17} \mathrm{Al}_{12}$, where $43.95 \mathrm{wt} \%$ of the compound is $\mathrm{Al}$ [16].

The Gibbs free energy of formation for the compound $\mathrm{Mg}_{17} \mathrm{Al}_{12}$ is $-6 \mathrm{~kJ} / \mathrm{mol}$. Within a temperature range of $700 \mathrm{~K}$ $1000 \mathrm{~K}$, the Gibbs free energy of formation increases to -3.9 $\mathrm{kJ} / \mathrm{mol}$. From the Gibbs free energy data, the $\mathrm{Mg}_{17} \mathrm{Al}_{12}$ intermetallic compound is expected to form first at the $\mathrm{Mg}$ interface. The Gibbs energy for the formation of the ternary compound $\mathrm{Ti}_{2} \mathrm{Mg}_{3} \mathrm{Al}_{18}$ was found to be approximate $15 \mathrm{~kJ} / \mathrm{mol}$. [19]. The width of the reaction layer that forms at the interface is believed to be time-dependent. As such, the layer thickness bears direct relation with growth kinetics. The average thicknesses of the $\mathrm{TiAl}_{3}$ and $\mathrm{Ti}_{2} \mathrm{Mg}_{3} \mathrm{Al}_{18}$ layers and the total intermetallic layer was used to determine the kinetic parameters involved in the diffusion process.
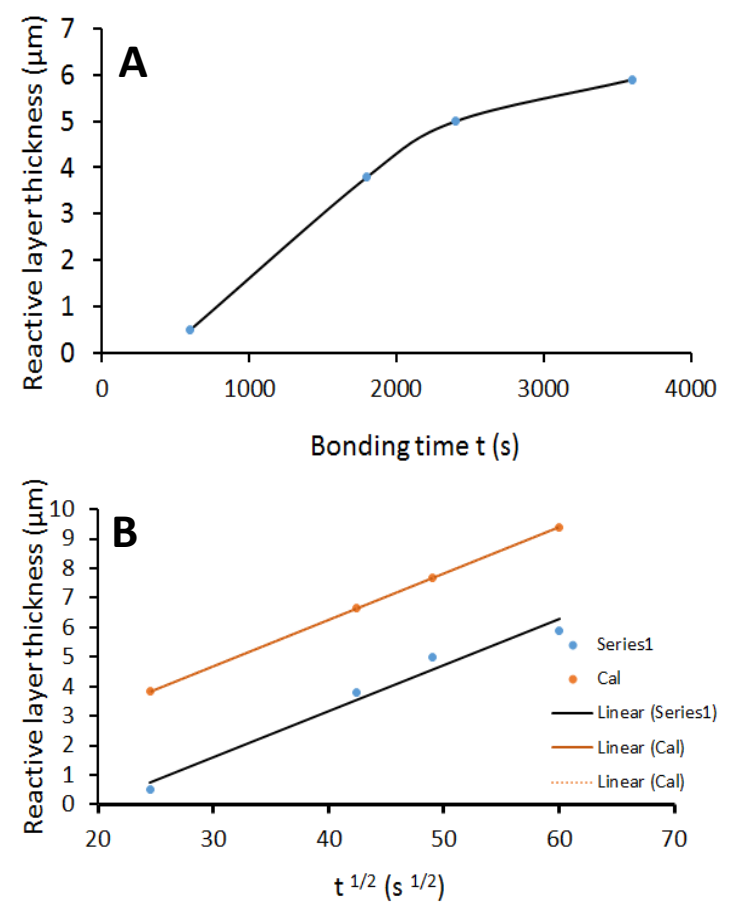

Fig. 5: (A) shows the relationship between the thickness of the reaction layer and the bonding time and (B) the predicted relationship between the width of the reaction layer and the bonding time according to the parabolic rate law.

The data collected shows that as the bonding time increases the width of the reaction layer also increased as predicted by the parabolic law shown in Equation 1. Fig. 5 shows the relationship between the bonding time and the thickness of the reaction layer formed at the interface and shows that as the bonding time increased, the width of the reaction layer also increased. When the parabolic rate law is applied to the results, the rate coefficient $k$ was calculated to be $15.7 \times 10^{-7}$ $\mathrm{m} / \mathrm{s}$. The value for $n$ was assumed to be 0.5 since the growth of the reaction layer was assumed to be controlled by interdiffusion. When the calculated rate coefficient is substituted into the power law shown in Equation 1, the results show that the model overestimated the width of the intermetallic layer was 1 . 


\section{G. Effect of interlayer composition on joint microstructure}

When a $\mathrm{Ni} / \mathrm{Al}_{2} \mathrm{O}_{3}$ electrodeposited coating was used as the interlayer, the interface was observed to contain three distinct regions as identified by the difference in the shade (Fig. 6). A light grey blocky structure surrounded by dark grey plate liked phases throughout the centre of reaction layer. Fig. 6 shows that diffusion took place predominantly on the magnesium side of the interface. When the bonds form was compared to the solid-state joint formed, it was observed that the width of the reaction layer was approximately twenty times thicker than the reaction layer formed during solid-state bonding of the same alloys. Additionally, several intermetallic compounds are at the interface during the bonding process.
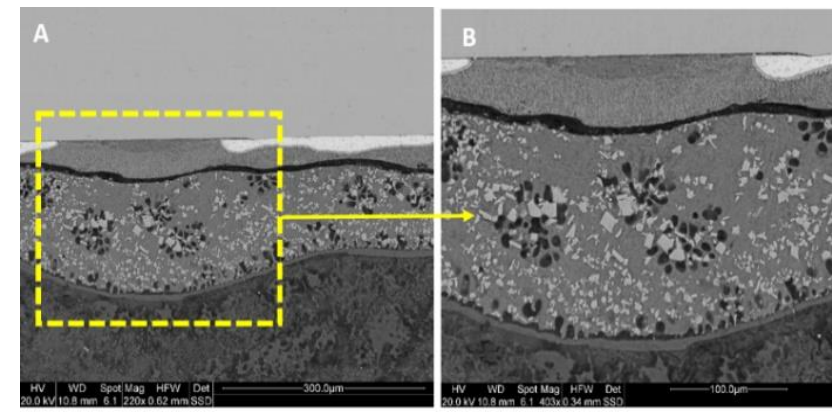

Fig. 6: $\mathrm{Ti}$ and $\mathrm{Mg}$ joint bonded using $\mathrm{Ni} / \mathrm{Al}_{2} \mathrm{O}_{3}$ interlayer for 60 minutes at $500{ }^{\circ} \mathrm{C}$.

\section{H. Hardness Measurements}

The effect of bonding time on the micro-hardness across the joint region is shown in Fig. 7. The microhardness values were measured across the joint starting at $500 \mu \mathrm{m}$ from the joint centre. The figure shows that the hardness of the Ti sample fluctuated from $390-420$ VHN up to $100 \mu \mathrm{m}$ from the joint centre as the bonding time was increased from 10 minutes to 60 minutes. The hardness within the joint centre was observed to decrease to $190 \mathrm{VHN}$ after 10 minutes bonding time and $250 \mathrm{VHN}$ after 60 minutes bonding time. The hardness of the Mg sample was found to be significantly lower than that of the Ti sample with a hardness ranging from 60 VHN after 10 minutes bonding time to $65 \mathrm{VHN}$. The variation of the hardness across the interface is attributed to the differences between the mechanical properties of $\mathrm{Ti}$ and $\mathrm{Mg}$. The hardness at the centre of the bond is believed to have been caused by the formation of the reaction layer at the joint interface [20]. The reaction layer was shown to be made-up of $\mathrm{TiAl}_{3}$ and $\mathrm{Ti}_{2} \mathrm{Mg}_{3} \mathrm{Al}_{18}$ intermetallic compounds dispersed within the joint region.

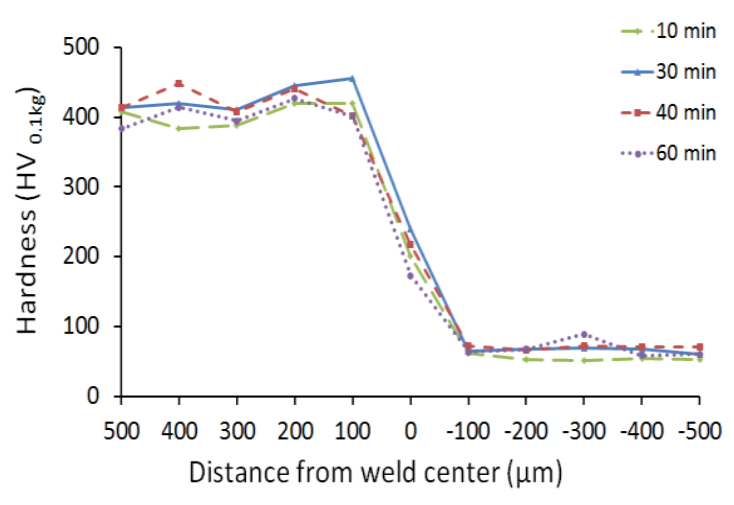

Fig. 7: Micro-hardness measurements across the joint region as a function of bonding time

\section{Shear strength measurements and fractography}

The effect of bonding time on the shear strength of $\mathrm{Ti} / \mathrm{Mg}$ solid-state bonds are presented in Fig. 8. The results show that as the bonding time increased, the shear strength of the bonds also increased from 15.6 MPa after 10 minutes bonding time to $116 \mathrm{MPa}$ after 60 minutes bonding time. The increase of the bond strength with bonding time was attributed to interdiffusion of $\mathrm{Ti}$, and $\mathrm{Mg}$ resulted in the formation of the compounds $\mathrm{TiAl}_{3}$ and $\mathrm{Ti}_{2} \mathrm{Mg}_{3} \mathrm{Al}_{18}$ as predicted by EDS analyses. When a $\mathrm{Ni} / \mathrm{Al}_{2} \mathrm{O}_{3}$ interlayer was used, the joint strength increased by more than $30 \%$ (see Fig. 9).

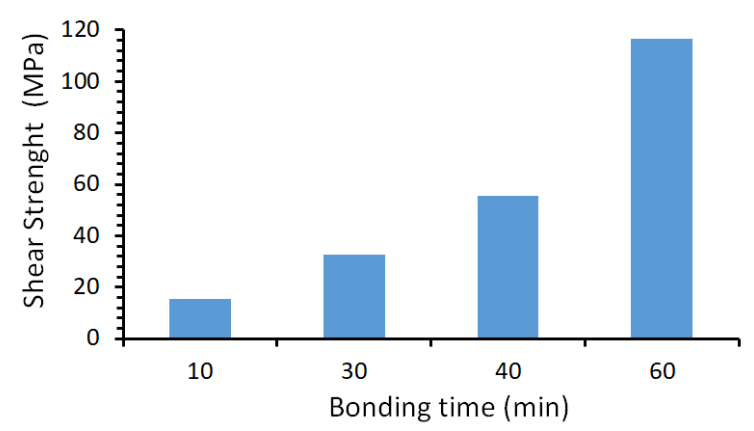

Fig. 8: Shear strength measurements as a function of bonding time

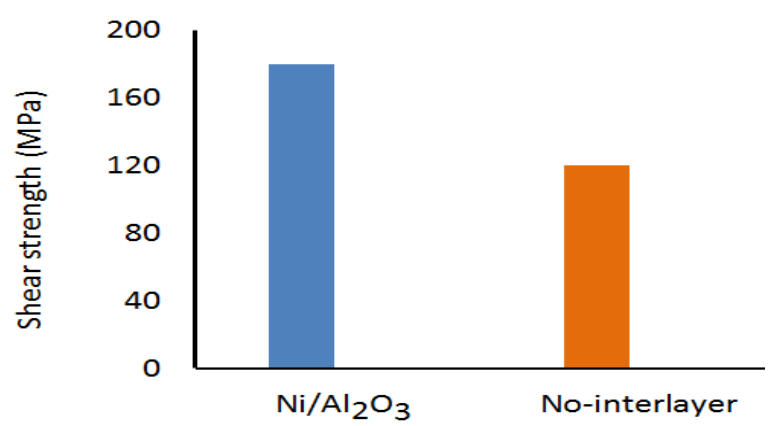

Fig. 9: Shear strength measurements as a function of interlayer composition

The precipitation of dispersed intermetallic compound served to reinforce the joint region causing an increase of the joint strength. The SEM micrograph presented in Fig. 10 shows the 
fractured surface for samples bonded for 60 minutes. The surface of the fractured sample showed evidence of a mixedmode of fracture due to the presence of both cleavage planes and micro-voids. Fig. 11 shows the XRD spectra for a sample bonded for 60 minutes. The spectra confirm the presence of several intermetallic compounds which are believed to be responsible for the type of failure observed. A schematic of the joint interface is presented in Fig. 12(A) and shows that fracture propagated through the $\mathrm{TiAl}_{3}$ and $\mathrm{Ti}_{2} \mathrm{Mg}_{3} \mathrm{Al}_{18}$ intermetallic phase present at the interface.
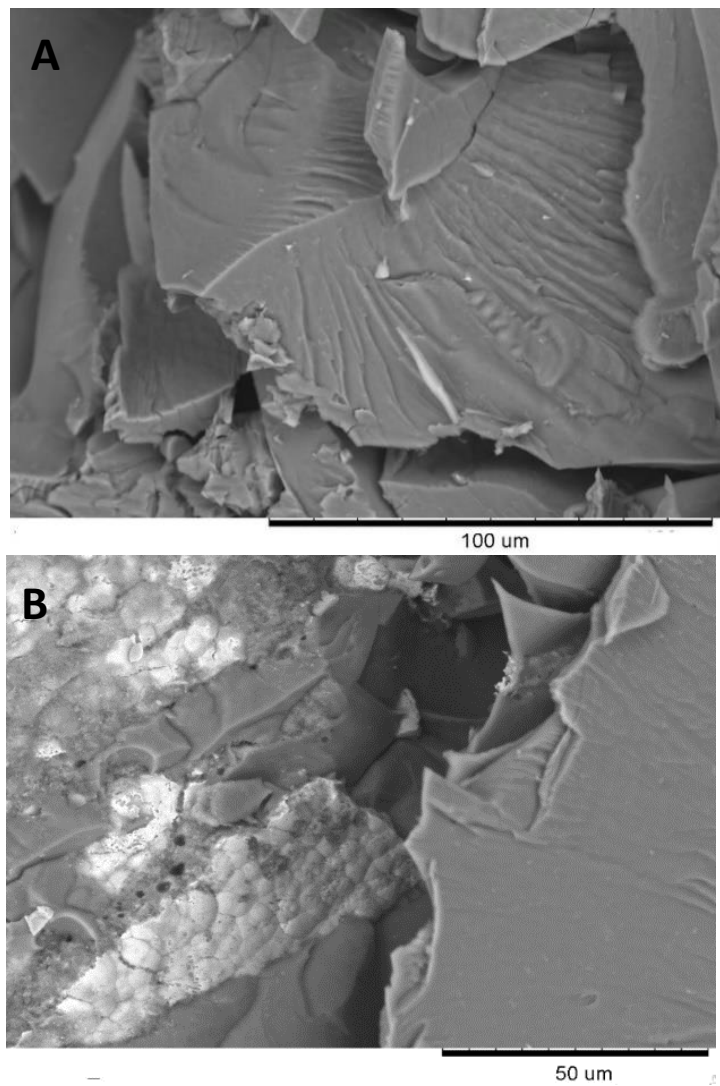

Fig. 10: (A)SEM micrograph of the Ti-side of the fractured surface for samples bonded for 60 minutes(B) SEM micrograph of the Mg-side of the fractured surface for samples bonded for 60 minutes.

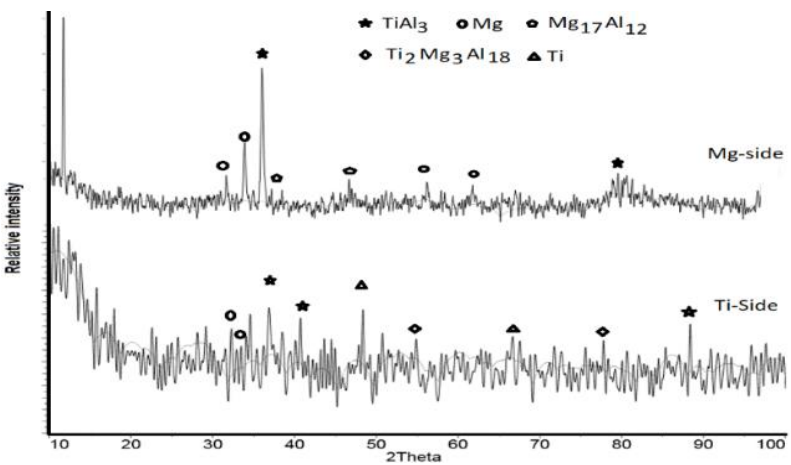

Fig. 11: XRD spectrum of the fractured surfaces of a sample bonded for 60 minutes
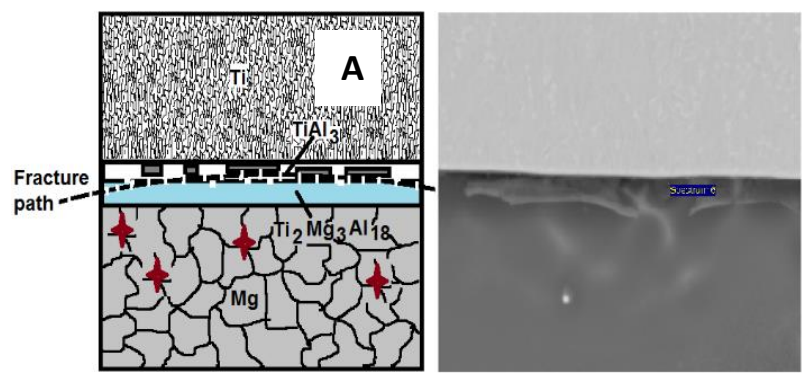

Fig. 12: (A) Schematic of the $\mathrm{Ti} / \mathrm{Mg}$ bond showing the fracture path (B) SEM micrograph of $\mathrm{Ti} / \mathrm{Mg}$ interface showing the reaction layer formed during bonding.

\section{CONCLUSION}

The objective of the study was to evaluate the potential of diffusion bonding Ti6Al-4V and $\mathrm{Mg}$ (Az31) and to study the microstructural evolution and intermetallic compounds formed within the bond region. The results of the study confirmed that $\mathrm{Ti}$ and $\mathrm{Mg}$ alloys containing $\mathrm{Al}$ could be joined successfully using solid-state diffusion bonding with or without an interlayer. The presence of $\mathrm{Al}$ leads to the precipitation of $\mathrm{TiAl}_{3}$ and $\mathrm{Ti}_{2} \mathrm{Mg}_{3} \mathrm{Al}_{18}$ intermetallic compounds at the interface which promoted strong a metallurgical bond between the $\mathrm{Ti}$ and $\mathrm{Mg}$ sample.

As the bonding time increase the strength of the bonds also increase. Variation of the bonding time from 10 minutes to 60 minutes, results in an increase of the bond strength from 15.6 $\mathrm{MPa}$ at 10 minutes to $116 \mathrm{MPa}$ at 60 minutes bond time. When an interlayer was used, the bond strength increased to 180 $\mathrm{MPa}$. The increase in joint strength was attributed to the formation of dispersed intermetallic compounds within the joint region. The presence of these compounds is believed to reinforce the interface by dispersion strengthening. Additionally, microstructural analysis of the bonds formed showed the absence of oxide layers which confirmed that quality joint could be made by solid-state joining.

\section{REFERENCES}

1. Kulekci, M.K. Magnesium and its alloys applications in automotive industry. Int. J. Adv. Manuf. Technol. 2008, 39, 851865

2. Kurt, H.I.; Guzelbey, I.H.; Salman, S.; Asmatulu, R.; Dere, M. Investigating the Relationships Between Structures and Properties of Al Alloys Incorporated With Ti and Mg Inclusions. J. Eng. Mater. Technol. 2016.

3. Zhong Y Liu ZK., Y.M. Contribution of first-principles energetics to $\mathrm{Al}-\mathrm{Mg}$ thermodynamic modelling. Calphad $\mathbf{2 0 0 5}$ $29,303-311$.

Khoshhal, R.; Soltanieh, M.; Mirjalili, M. Formation and growth of titanium aluminide layer at the surface of titanium sheets immersed in molten aluminum. Iran. J. Mater. Sci. Eng. 2010.

Hehmann, F.H.F.-W.K. Rapid Solidification of Al, Mg and Ti. $J$. Miner. Met. Mater. Soc. 1987, 39, 14-21.

6. Liu L and Liu. A, R.D. Review of Dissimilar Welding Techniques for Magnesium Alloys to Aluminum Alloys . Mater. Charact. 2014, 7, 3735-3757.

7. Paul Kah Jukka Martikainen, Carl Magnus, R.S. Techniques for joining dissimilar materials: Metals and polymers. Rev. Adv. 
Mater. Sci. 2014, 36, 152-164.

8.

Cooke, K.O.; Khan, T.I. Resistance spot welding aluminium to magnesium using nanoparticle reinforced eutectic forming interlayers. Sci. Technol. Weld. Join. 2017, 23, 271-278.

C. Xu Y. Q. Deng, X. J. Yuan and K. L. Tang, G.M.S Microstructure and mechanical properties of tungsten inert gas welded-brazed Mg/Ti lap joints. Sci. Technol. Weld. Join. 19, 443-450.

Akhtar, T.S.; Cooke, K.O.; Khan, T.I.; Shar, M.A. Nanoparticle enhanced eutectic reaction during diffusion brazing of aluminium to magnesium. Nanomaterials 2019

11. Khan, A.M.A. and T.I. Transient liquid phase (TLP) brazing of $\mathrm{Mg}-\mathrm{AZ} 31$ and $\mathrm{Ti}-6 \mathrm{Al}-4 \mathrm{~V}$ using $\mathrm{Ni}$ and $\mathrm{Cu}$ sandwich foils. Sci. Technol. Weld. andJoining, 2014, 19, 333-342.

12. Cooke, K.O.; Khan, T.I.; Oliver, G.D. Effect of $\mathrm{Ni}^{-\mathrm{Al}^{2} \mathrm{O}^{3}}$ nanocomposite coating thickness on transient liquid phase bonding of al 6061 MMC. Sci. Technol. Weld. Join. 2012, 17.

13. Liu, L.; Ren, D.; Liu, F. A review of dissimilar welding techniques for magnesium alloys to aluminum alloys. Materials (Basel). 2014, 3735-3757.

14. Kah, P.; Suoranta, R.; Martikainen, J.; Magnus, C. Techniques for joining dissimilar materials: Metals and polymers. Rev. Adv.
Mater. Sci. 2014, 16, 229-237.

15. Kajihara, A.F. and M. Numerical Analysis for Kinetics of Reactive Diffusion Controlled by Boundaryand Volume Diffusion in a Hypothetical Binary System. Mater. Trans. 2008, 49, 294 303.

16. Kajihara, M.O. and M. Kinetics of Solid-State Reactive Diff usion between Au and Al. Mater. Trans. 2011, 52, 677-684.

17. Cooke, K.O. Parametric Analysis of Electrodeposited Nanocomposite Coatings for Abrasive Wear Resistance. In Electrodeposition of Composite Materials; Mohamed, A.M.A., Golden, T.D., Eds.; InTech: Rijeka, 2016; p. Ch. 09.

18. Cooke, K.O. Effect of thermal processing on the tribology of nanocrystalline $\mathrm{Ni} / \mathrm{TiO} 2$ coatings. 2018.

19. Effenberg G., I.S. Part 3. Landolt-Börnstein - Group IV Physical Chemistry (Numerical Data and Functional Relationships in Science and Technology), . In Materials Science International Team MSIT® () Al-Mg-Ti (Aluminium - Magnesium - Titanium). In: . Light Metal Systems; Effenberg G., I.S. (eds), Ed.; Springer: Berlin, Heidelberg, 2011; Vol. vol 11A3.

20. A. AlHazaa I. Haq, T.I.K. Transient liquid phase (TLP) bonding of Al7075 toTi-6Al-4V alloy. Mater. Charact. 2010, 61, 312317. 